\title{
Assessment of Scapula Muscle Strength in Housemaids
}

\author{
Riddhi Shroff ${ }^{1}$, Ankita Jain ${ }^{2}$ \\ ${ }^{\text {I} A s s i s t a n t ~ P r o f e s s o r, ~ S c h o o l ~ o f ~ P h y s i o t h e r a p y, ~ D . Y . ~ P a t i l ~ U n i v e r s i t y, ~ N e r u l, ~ N a v i ~ M u m b a i, ~}$ \\ ${ }^{2}$ Clinical Physiotherapist, Bangalore, D. Y. Patil Hospital, Nerul, Navi Mumbai-40005
}

\begin{abstract}
Introduction: Neck and upper limb musculoskeletal disorders are a major source of disability which is also resulting in economic loss. Housemaids are exposed to repetitive tasks which causes them to be at high risk of neck pain. This result in increased burden on health care costs and also adds to reduced work productivity. The aim of the study is to evaluate scapula muscle strength in housemaids to determine magnitude of the problem.
\end{abstract}

Methodology: A total of 100, divided as 50 participants in housemaid group with neck pain and 50 age matched normal individuals in the asymptomatic group were recruited for the study. Self made questionnaire and scapula muscle strength were tested using push - pull dynamometer.

Results and Discussion: The study highlights the weakness of scapula muscle strength with neck pain in housemaids as compared to asymptomatic group. This gives us an insight into significance of scapula muscle strength in neck pain cases which will help us in formulating effective treatment strategies for treating neck pain cases.

Keywords: Neck, Pain, Housemaids, Strength, Scapula.

\section{Introduction}

Neck pain is a commonly treated musculoskeletal condition by health care professionals. It has been estimated that the annual prevalence of neck pain in the general population is $30-50 \%$ with the prevalence of activity limitations due to neck pain ranging between $11-14 \% .^{[1,2]}$

Neck and upper limb Musculoskeletal Disorders (MSDs) represent a major source of disability globally and have resulted in a major socio-economic affection..$^{[3,4,5]}$ The majority of individuals who experience acute neck pain symptoms do not seek medical care, which further progresses to chronic neck pain. It has a prolonged negative impact on health care expenditures. ${ }^{[6]}$

\section{Corresponding Author:}

\section{Riddhi Shroff}

Postal Address: B/19, Modi Nagar, Mathuradas road,

Kandivali West, Mumbai-400067

Mobile: 9769491687

e-mail: riddhishroff89@gmail.com
Housekeeping is a physically challenging job which requires repetitive tasks specially with upper limb. There arevarious push-pull activities that stresses biomechanical structures which leads to exposure of many high-risk factors for neck and upper limb (MSDs). ${ }^{[7,8,9]}$ Studies conducted across countries have demonstrated a high magnitude of the neck and upper $\operatorname{limb}$

MSDs among housekeepers. ${ }^{[7,10,11,12]}$ Coming to India, where lower socioeconomic strata of women are involved as housemaids for maximum hours in a day, which involves extensive household chores that predisposes them to a constant risk of developing various neck and upper limb related musculoskeletal disorders.

Previous studies have demonstrated impaired cervical flexor muscle performance in subjects with neck pain. ${ }^{[13]}$ Exercises directed toward these muscles has been shown beneficial. ${ }^{[14]}$ There is emerging evidence that scapulothoracic muscle weakness may also be associated with neck pain. ${ }^{[15,16]}$

The purpose of this study was to examine 
scapulothoracic muscle strength in housemaids on the side of neck pain compared to the unaffected side. A second purpose was to compare muscle strength of housemaids with age matched normal subjects without neck pain.

\section{Materials and Method}

After the institutional ethics committee approval. 50 participants in housemaid neck pain group and 50 age matched normal individual in the asymptomatic group were recruited for the study in the age group of 18 and 60 years of age.

Housemaid Neck Pain group had to have one of the following- Central and/or unilateral neck pain for more than 1 month, Limitation in neck range of motion, referred shoulder girdle or upper extremity pain.

To be included in the asymptomatic group, participants should have no complaint of neck and shoulder pain. Individuals were excluded from either group if they had evidence of central nervous system involvement, pathological reflexes, or demonstrated positive neurologic signs consistent with nerve root compression. Individuals were not eligible to participate if they reported previous spinal surgery.
Procedure: Five Scapula-humeral muscle groups were tested with Hydraulic Push-Pull Dynamometer. During testing of External and Internal rotators of Shoulder joint,subjects were seated with proper body alignment in a high sitting position, with towel roll under the axilla, and with both feet placed flat on the foot stool. Middle and lower trapezius were checked by adopting prone position with towel placed under the forehead. Modified Kendall position was used to test serratus anterior in supine position. The "break test" was used for the testing procedures. ${ }^{[17]}$

The maximal force is resisted by the examiner, applied by the subject. The "breaking force" is the amount of force required to overcome a maximal effort muscle contraction in order to move the limb from the initial starting position. ${ }^{[18]}$ Three trials were done for all the muscles were tested using this technique.

\section{Results}

Table 1: Demographic Details

\begin{tabular}{|l|c|c|}
\hline Variable & $\begin{array}{c}\text { Neck Pain } \\
\text { group }\end{array}$ & $\begin{array}{c}\text { Asymptomatic } \\
\text { group }\end{array}$ \\
\hline Age & $42 \pm 3.41$ & $42 \pm 3.41$ \\
\hline Duration of working (hours) & $14 \pm 1.24$ & $10 \pm 1.77$ \\
\hline Rest periods (hours) & $1 \pm 0.66$ & $1 \pm 0.85$ \\
\hline
\end{tabular}

Table 2: Intra Group Strength

\begin{tabular}{|l|c|c|c|}
\hline Variable & Painful side & Non Painful side & P value \\
\hline External Rotators & 3.97 & 4.33 & 0.001 \\
\hline Internal Rotators & 4.52 & 5.39 & 0.000 \\
\hline Middle Trapezius & 6.94 & 7.43 & 0.000 \\
\hline Lower Trapezius & 6.88 & 7.38 & 0.001 \\
\hline Serratus Anterior & 8.85 & 9.26 & 0.001 \\
\hline
\end{tabular}

Table 3: Inter Group Strength

\begin{tabular}{|l|c|c|c|}
\hline Variable & Neck Pain group & Asymptomatic group & P value \\
\hline External Rotators & 3.97 & 4.55 & 0.000 \\
\hline Internal Rotators & 4.52 & 5.45 & 0.000 \\
\hline Middle Trapezius & 6.94 & 7.50 & 0.000 \\
\hline Lower Trapezius & 6.88 & 7.78 & 0.000 \\
\hline Serratus Anterior & 8.85 & 9.51 & 0.000 \\
\hline
\end{tabular}




\section{Discussion}

The results of this study suggest statistically significant lower scapulothoracic muscle strength values in housemaids with neck pain compared to asymptomatic individuals. The mean scores of the strength values were lower on the painful side in housemaids with neck pain. There is a strong interrelationship between chronic neck and scapula dysfunction. This can be attributed to close association between the scapula and the cervical spine which is connected through the axioscapular muscles. ${ }^{[19,20]}$

One potential reason for impaired scapulothoracic muscle strength in housemaids with neck pain is during strength testing,subjects did not exert maximum effort as pain might be a barrier. ${ }^{[21]}$ Secondly,our study shows that housemaids are involved in long working hours with inadequate rest breaks. This results in prolonged repetitive movements which is exhausting. Also, the worker is unable to recover in the short rest periods of time between work duration, thus exposing at increased neck and upper limb MSDs. ${ }^{[22]}$

In our study, the scapula muscle strength of subjects with neck pain were significantly weaker on the affected side of neck pain as compared to asymptomatic group. These changes in scapular kinematics can also be associated to altered serratus anterior muscle recruitment pattern also, muscle performance such as force imbalance in the upper and lower trapezius muscle,and flexibility deficits in the anatomical location surrounding the scapula which may restrict normal scapular movement during daily activity. ${ }^{[23-26]}$ Movement pattern correction plays a vital role of muscle-recruiting strategies in rehabilitation.

Recovering the normal activation of the serratus anterior and trapezius muscles is essential for neck and shoulder disorder rehabilitation. ${ }^{[27]}$ Proper firing patterns and recruitment of muscles require coupling of the serratus anterior muscle with the upper, middle, and lower trapezius muscles, consequently resulting in "force couples," which are considered necessary fornormal scapular orientation. ${ }^{[28,}{ }^{29}$ Previous study have shown that the main goal was to inhibit the over activity of muscle and to facilitate the muscle with weak activity for postural control. ${ }^{[27]}$

Thus, the early diagnosis of scapula muscle involvement in neck pain in housemaids will help in planning effective interventions which can help the housemaids with limitations faced in their work activities.

\section{Conclusion}

The study demonstrates statistically significant weakness of scapula muscle strength with neck pain in housemaids as compared to asymptomatic groups. This gives us an insight into significance of scapula muscle strength in neck pain cases which will help us in formulating effective treatment strategies for treating neck pain cases.

Ethical Clearance: It is obtained from institutional ethics committee

Source of Funding: It is self funded

\section{Conflict of Interest: Nil}

\section{References}

1. Hogg-Johnson S, van der Velde G, Carroll LJ,Holm LW, Cassidy JD, Guzman Jet al. The burden anddeterminants of neck pain in the general population: results of the Boneand Joint Decade 2000-2010.Task Force on Neck Pain and its associated Disorders. J Manip Physiol Ther 2009; 32(2 Suppl):46-60.

2. Cote P, van der Velde G, Cassidy JD, Carroll LJ, Hogg-Johnson S, Holm LWet al. The burden and determinants ofneck pain in workers: results of the Bone and Joint Decade 2000-2010Task Force on Neck Pain and Its Associated Disorders. J Manip Physiol. Ther 2009; 32(2 Suppl):70-86.

3. Coyte PC, Asche CV, Croxford R, Chan B. The economic cost of musculoskeletal disorders in Canada. Arthritis Rheum 1998;11:315-25.

4. Mäkelä $M$, Heliövaara $M$, Sievers $K$, Knekt $P$, Maatela J, Aromaa A. Musculoskeletal disorders as determinants of disability in Finns aged 30years or more. J Clin Epidemiol. 1993;46:549-59.

5. Picavet H, Schouten J. Musculoskeletal pain in the Netherlands: prevalences,consequences and risk groups, the DMC 3-study. Pain 2003;102:167-78

6. Nordin M, Carragee EJ, Hogg-Johnson S, et al: Assessment of neck painand its associated disorders: results of the Bone and Joint Decade 2000-2010. Task Force on Neck Pain and Its Associated Disorders. Spine 2008;33(4 Suppl):101-122.

7. European Agency for Safety and Health at 
Work: E-fact 39 - Cleaners andmusculoskeletal disorders. 2008. https://osha.europa.eu/en/toolsandpublications/publications/e-facts/efact39.

8. Bell AF, Steele JR. Risk of musculoskeletal injury among cleaners duringvacuuming. Ergonomics 2012;55:237-47.

9. Canadian Centre for Occupational Health and Safety: HotelHousekeeping. 2016.https://www. ccohs.ca/oshanswers/occup_workplace/hotel_ housekeeping.html

10. El Tayeb I, Ghareeb N, Zalat M. Prevalence of musculoskeletal problemsamong full time lady servants in Doqqi area, Cairo.Egypt J Occup Med 2013;37:47-59.

11. Mammen R. Assessment of physical workload, ergonomic problems and prevalence of pain among low wage hotel housekeepers in Orlando; 2017.

12. Frumin E,Joan M, Pamela V, John H, Peter O, Niklas $\mathrm{K}$ et al.Workload-related musculoskeletal disorders among hotel housekeepers: employer records reveal a growing national problem; 2006.

13. Falla D, Jull G, Hodges P. Patients with neck pain demonstrate reduced electromyographic activity of the deep cervical flexor muscles during performance of the craniocervicalflexion test. Spine 2004; 29(19): 2108-2114.

14. Jull GA, Falla DL, Vicenzino B, Hodges PW. The effect of the rapeutic exercise on activation of the deep cervical flexormuscles in people with chronic neck pain. Man Ther 2009;14(6): 696-701.

15. Petersen SM, Wyatt SN. Lower trapezius muscle strength in individuals with unilateral neck pain. J Orthop Sports Phys Ther 2011; 41(4): 260-265.

16. Shahidi B, Johnson C, Curran-Everett D, Maluf $\mathrm{K}$. Reliabilityand group differences in quantitative cervicothoracic measuresamong individuals with and without chronic neck pain. BMC Musculoskelet Disord 2012; 13: 215

17. Guihem G, Cornu C, Guevel A. Neuromuscular and muscle-tendon system adaptions to isotonic and isokinetic eccentric exercise. Ann Phys Rehab Med 2010; 53:319-341.

18. Lewis VM, Merritt JL, Piper SM, Sinaki M. Correlations between isotonic and isometric measurements of trunk muscle strength. Arch Phys Med Rehabil 1987; 68:639.
19. Behrsin JF, Maguire K. Levator scapulae action during shoulder movement: A possible mechanism for shoulder pain of cervical origin. Aust J Physiother 1986;32:101-6.

20. Gwendolen J,Michele S, Deborah F,Julia T,Shaun L.Whiplash, headache and neck pain. 1st edn. Churchill Livingstone, 2008.

21. Shannon M. P, Nathan A.D, Chad E.C. Scapulothoracic muscle strength inindividuals with neck pain. Journal of Back and Musculoskeletal Rehabilitation 2016;29: 549-555.

22. Sintayehu D.W, Awrajaw D, Daniel H.C. The impact of work-related risk factors on the development of neck and upper limb pain among low wage hotel housekeepers in Gondar town, Northwest Ethiopia: institution-based cross-sectional study. Environmental Health and Preventive Medicine 2019;24:27.

23.Ludewig PM, Cook TM. Alterations in shoulder kinematics and associated muscle activity in people with symptoms of shoulder impingement. Phys Ther 2000;80:276-91.

24. Cools AM, Witvrouw EE, Declercq GA, et al. Scapular muscle recruitment patterns: trapezius muscle latency with and without impingement symptoms. Am J Sports Med 2003;31:542-9.

25. Borstad JD, Mathiowetz KM, Minday LE, et al. Clinical measurement of posterior shoulder flexibility. Man Ther 2007;12:386-9.

26. Borich MR, Bright JM, Lorello DJ, et al. Scapular angular positioning at end range internal rotation in cases of glenohumeral internal rotation deficit. J Orthop Sports Phys Ther 2006;36:926-34.

27. Boyoung Im, Young Kim, Yijung Chung, Sujin Hwang. Effects of scapular stabilization exercise on neck posture and muscle activation in individuals with neck pain and forward head posture.J. Phys. Ther. Sci 2016. 28: 951-955.

28. Lindstrøm R, Schomacher J, Farina D, et al. Association between neck muscle coactivation, pain, and strength in women with neck pain. Man Ther 2011, 16: 80-86.

29. Wegner S, Jull G, O'Leary S, et al. The effect of a scapular postural correction strategy on trapezius activity in patients with neck pain. Man Ther 2010, 15: $562-566$ 